artigo $]$

[EMANUELLE KELLY R. SILVA]

Doutora em Educação pela Universidade Federal do Ceará (2015), professora do Curso de Graduação em Design-Moda da mesma instituição .

E-mail: emanukelly@gmail.com

\title{
A relação entre designers de moda e artesãos na perspectiva da educação emancipatória
}

\author{
The relationship between \\ fashion designers and artisans \\ in education perspective \\ emancipatory
}

[resumo] 0 presente trabalho aborda as novas formas de produção do artesanato a partir das intervenções de políticas públicas voltadas para o desenvolvimento dessa atividade. Tomando como parâmetro as trocas de saberes e fazeres entre artesãos e designers no Estado do Ceará, enfoca as interferências pedagógicas dos designers no processo criativo e produtivo dos artesãos.

palavras-chave

metodologia; educação; design e artesanato.

[abstract] This paper discusses new forms of handicraft production from policy interventions aimed at the development of this activity. Taking as parameter the exchange of knowledge and practices between artisans and designers in the state of Ceará, focuses on the pedagogical interference of this professional in the creative and production process of the craftsmen.

[keywords] methodology; education; design and craft. 
Designers, artesãos e o contexto das intervenções na produção artesanal

0 artigo deriva de uma série de dados documentais e empíricos colhidos durante a pesquisa de doutorado' sobre as relações de saberes entre designers e artesãos no interior do Ceará, Brasil. A observação da relação estabelecida entre designers e artesãos no contexto das intervenções voltadas para o desenvolvimento e a atualização do artesanato no Estado levanta uma série de questionamentos sobre o tipo de formação que vem sendo dada aos designers responsáveis por aplicar as metodologias de design na produção artesanal.

A partir de entrevistas realizadas com 18 designers (estudantes e profissionais) que atuam nesse campo, pode-se perceber que há, ainda, muita incerteza sobre a prática empreendida no cotidiano das intervenções no artesanato. Portanto, este texto tem como objetivo apresentar os conflitos enfrentados por designers que lidam com a delicada tarefa de criar e desenvolver novos produtos junto aos grupos de artesãos, sendo preciso, para isso, "ensinar" outros processos de criação e produção, diferentes daqueles que os próprios artesãos empregam tradicionalmente em seu ofício.

A metodologia adotada para o desenvolvimento da pesquisa foi a observação participante, uma vez que atuei junto aos artesãos como designer e também compartilhei experiências com outros designers que desenvolvem ações junto aos artesãos. De acordo com Gonçalves (2005, p. 69), "nas observações participantes, o pesquisador integra-se à comunidade ou ao grupo que investiga, participando de suas atividades normais", de modo que o pesquisador pode vivenciar o que o grupo vivencia e participar do mesmo sistema de referência dele. Outras ferramentas metodológicas também foram utilizadas, como diário de campo, entrevistas, conversas informais, estudo de documentos e materiais bibliográficos.

Ao longo do estudo, a maioria dos designers entrevistados informou que não está segura quanto ao método de atuação junto aos artesãos e às possibilidades e aos limites de seu trabalho com o artesanato.

Dentre os principais "achados" da pesquisa, podemos citar o papel pedagógico do designer no contexto das intervenções junto aos artesãos. Com a interpretação dos depoimentos dos designers e a observação do cotidiano de suas ações, foi possivel perceber que, além da função de projetistas, esses profissionais também assumem a responsabilidade de repassar conhecimentos relacionados ao design de produto aos artesãos.

0 acompanhamento dos projetos voltados para o desenvolvimento do artesanato ${ }^{2}$ e a observação de sua metodologia também comprovaram que há interesse por parte das entidades promotoras em qualificar os artesãos de modo que estes possam dinamizar sua produção por meio da atualização dos produtos e da observação das demandas do mercado. Para tanto, a maioria das ações de instituições voltadas ao desenvolvimento do artesanato ${ }^{3}$ é baseada no recrutamento de designers que, por sua vez, são encaminhados aos grupos de artesãos em diferentes localidades do Estado do Ceará, a fim de que eles, por meio de cursos de capacitação, desenvolvam junto com os artesãos produtos mais atrativos para o mercado, seja pela agregação de novas funcionalidades, seja pelo apelo estético.

Em suma, as ações desenvolvidas junto aos artesãos são baseadas no interesse em fazer com que eles passem a desenvolver produtos condizentes com as demandas de moda e do mercado e, para isso, é importante que eles adquiram habilidades relacionadas ao manuseio de ferramentas de design, como foi possivel observar ao longo da pesquisa de campo. Nesse sentido, é o designer que acaba sendo o responsável por apresentar noções de design referentes principalmente a combinações de cores, desenvolvimento de formas, pesquisas iconográficas, entre outras técnicas, aos artesãos.

Com isso, o designer passa a assumir uma posição junto aos artesãos semelhante à do professor em sala de aula, pois, no contexto das intervenções, ele é o responsável 
pelo desenvolvimento das atividades e pela "capacitação" dos artesãos, além de controlar a qualidade dos produtos desenvolvidos.

Assim, constata-se que o designer, ao mesmo tempo que desenvolve o produto, deve "ensinar" aos artesãos o processo de como isso é feito a fim de que eles incorporem a metodologia apreendida no cotidiano de seu ofício. Disso decorre a função pedagógica do designer no contexto do trabalho com os artesãos, função esta que é, na maioria das vezes, ofuscada pela prática do processo de desenvolvimento do produto.

Com a finalidade de apresentar de maneira mais detalhada os aspectos e reflexões previamente apresentados nesta introdução, o presente artigo foi organizado em mais duas seções que se desdobram a seguir. A primeira delas aborda justamente as preocupações dos designers em relação ao seu trabalho junto aos artesãos; e a última apresenta uma análise sobre o designer e seu papel junto aos artesãos sob a perspectiva da educação emancipatória, seguida pelas considerações finais.

\section{O papel "pedagógico" do designer em seu trabalho junto aos artesãos}

0 estudo realizado em campo abriu caminho para a compreensão de que o designer, além de projetar novos produtos, também atua como mediador na "transmissão" de novos conhecimentos aos artesãos. Ao longo desta seção serão apresentadas algumas reflexões a respeito da relação designer/artesão que perpassam por essa questão. Optamos por lançar mão da transcrição de depoimentos dos próprios designers acerca de sua experiência com o trabalho dos artesãos, sem deixar de apontar aspectos relevantes desenvolvidos por teóricos e estudiosos do assunto, como Canclini (2008) e Mendes (2011).

Entre os temas mais abordados durante as conversações com os designers entrevistados, destacaram-se a preocupação com o curto período de tempo destinado às intervenções, que não favorecia o amadurecimento do contato com os artesãos, e o desenvolvimento de projetos com maior embasamento nas características culturais locais e, portanto, mais próximos dos anseios dos produtores. Como observamos nos depoimentos abaixo:

Como podemos ampliar e otimizar o período de contato com os artesãos durante a visita de diagnóstico? (Designer 2, em 14 de agosto de 2013)

Acho pouco o tempo dedicado à primeira visita ao grupo. Nessa única visita de diagnóstico, que geralmente dura uma tarde, temos que traçar o perfil do grupo, perceber suas necessidades e seus anseios, conhecer a qualidade dos trabalhos que desenvolvem e sua habilidade técnica, fotografar a localidade e ainda identificar os ícones locais e culturais necessários para o desenvolvimento de uma coleção consistente, de acordo com os moldes da Ceart. É pouco tempo para muita coisa! (Designer 1, em 14 de agosto de 2013)

Tal preocupação dos designers com o prazo das intervenções é uma constante. Observou-se que o tempo dedicado à visita de diagnóstico, momento determinante para a orientação do restante do processo intervencionista, é muito incipiente. Haja vista que, em apenas um período do dia (manhã ou tarde), o designer deve conhecer o grupo, registrar suas habilidades, expectativas e limitações e ainda buscar referências culturais e imagéticas para fundamentar a construção da coleção e do projeto de intervenção.

Segundo a coordenadora das atividades da Ceart (Central de Artesanato do Ceará), a razão desse formato adotado na visita de diagnóstico deve-se à limitação de verbas destinadas ao custeio das passagens e da estadia do designer nas cidades nas quais o grupo de artesãos assistido pelo projeto se situa.

Outro questionamento levantado durante um seminário da Ceart foi relacionado à metodologia de intervenção adotada pelos profissionais envolvidos no processo. Apesar de haver orientações da entidade voltadas para a sistematização das intervenções que se dão a partir de uma série de procedimentos previamente delimitados, 
alguns designers mostraram-se preocupados com a falta de parâmetros metodológicos mais específicos que norteassem o cotidiano das intervenções.

Como podemos chegar a uma metodologia comum nessas intervenções? (Designer 1, depoimento colhido em 14 de agosto de 2013)

Será que nós podemos utilizar esse método de fazermos dinâmicas junto com os artesãos para que eles possam criar junto com os designers? (Designer 3, depoimento colhido em 14 de agosto de 2013)

A preocupação com a metodologia adotada durante as intervenções relaciona-se diretamente à necessidade de dedicar mais "cuidado" ao trabalho do artesão no contexto das intervenções e à busca por otimizar os resultados alcançados. Esse também foi um dos aspectos mais apontados e debatidos entre os designers:

Devemos prestar atenção nos sonhos e interesses dos artesãos para podermos criar de acordo com seus anseios, não a nossa coleção, mas a coleção deles. (Designer 4, em 14 de agosto de 2013)

Tivemos experiências em que os artesãos não conseguiram confeccionar os artigos projetados por um designer porque este desenvolveu uma coleção baseada em folhas secas e os artesãos não se identificaram com isso, eles buscavam cores e outros elementos, era isso que eles queriam mostrar. As folhas secas faziam parte da vida deles, mas não era isso que eles queriam mostrar. (Técnica da Ceart 1, em 14 de agosto de 2013)

Uma designer, certa vez, desenvolveu um trabalho com bonecos de pano em uma comunidade quilombola. A designer criou bonecos utilizando cores pretas e marrons, sapecado, mas os artesãos não se identificaram, eles não se reconheceram e gostavam de desenvolver bonecos cor-de-rosa e com lãs. (Técnica da Ceart 2, em 14 de agosto de 2013)

0 artesão deve se reconhecer no trabalho que está sendo feito. (Designer 5, em 14 de agosto de 2013)

Até que ponto o designer tem autonomia para desenvolver um trabalho de vanguarda? Até que ponto a nossa criatividade nos permite extrapolar alguns limites? Ou seja, como posso utilizar elementos que casem com o desejo do público da Ceart? (Designer 3, em 14 de agosto de 2013)

Temos várias funções, pois temos que atender a vários desejos, o do público-alvo, do artesão, a questão social etc. (Designer 6, em 14 de agosto de 2013)

Como pôde ser observado pelas questões apontadas e pelos depoimentos dos designers, ainda estamos longe de compreender ou definir os limites e as possibilidades quando o assunto é a intervenção de design no artesanato. Outro ponto que merece destaque é que os artesãos também impõem seus próprios limites quando não se reconhecem no trabalho a ser realizado. Tais fatos expostos nos depoimentos revelam muito das negociações e dos conflitos que podem surgir entre designers e artesãos no contexto das intervenções. 
De acordo com Canclini (2008), as identidades se constituem não só no conflito bipolar entre as classes, mas também em contextos institucionais de ação cujo funcionamento se torna possível na medida em que todos os seus participantes, hegemônicos ou subalternos, concebem uma ordem negociada. Nesse sentido, ao mesmo tempo que as classes populares afirmam em espaços ou em rituais específicos sua identidade originária, elas também podem reformular seu patrimônio cultural assimilando saberes e costumes que lhes permitem se reposicionar em novas relações socioculturais políticas e de trabalho.

Logo, compreendemos que o papel das entidades, bem como dos designers que lidam diretamente com os artesãos, nem sempre responde a uma atitude salvacionista ou predatória do trabalho dos artesãos, mas os designers também estabelecem negociações com os artesãos a fim de viabilizar o desenvolvimento de produtos que gerem retorno para o mercado.

A partir dos depoimentos, percebemos que os artesãos, por sua vez, não aceitam as propostas dos designers de forma passiva, mas reagem de diversas maneiras, conforme suas representações e seus valores, como foi o caso da comunidade quilombola que se recusou a confeccionar bonecas de pano negras e do grupo que não quis retratar folhas secas em seus trabalhos.

A recusa dos artesãos em desenvolver algo que eles consideram que não os representa faz parte das inúmeras contingências que podem emergir durante as intervenções de design no artesanato e que não estão previstas na Apostila de Metodologia Projetual, por exemplo. No processo de intervenção, o produto é construído mediante as negociações estabelecidas entre artesãos e designers e as interseções de saberes e fazeres que nascem do contato entre designers e artesãos.

Diante dessas circunstâncias é que o debate acerca desse contato e o compartilhamento, entre os designers, das situações inesperadas que surgem a partir dele merece mais atenção do que a "simples" revisão de conteúdos do design. 0 cerne da questão não está no que se deve ou não fazer, mas no como fazer.

Esse ponto é imprescindivel para que compreendamos as ações empreendidas pelos designers junto aos artesãos e as modificações ocorridas no processo produtivo destes a fim de que seu produto atenda às exigências do mercado.

Entendendo-se que as metodologias de design são implementadas no artesanato tendo como foco o produto final, ou seja, a peça pronta, muitos designers e estudiosos esforçam-se em apresentar resultados positivos de intervenções diversas, outros centram-se nos processos e nos métodos de obtenção/otimização da matéria-prima, na exploração da técnica artesanal ou nas possibilidades de inovação que 0 artesanato oferece (ESTRADA, 2004; FREITAS, 2006; LIMA, 2006).

No entanto, acreditamos que a problemática central não seja a criação de uma metodologia adequada ou padrão para as intervenções, até porque estas não divergem apenas em relação à tipologia do artesanato desenvolvida em um grupo de artesãos, mas, principalmente, porque os próprios artesãos são indivíduos únicos e diferentes entre si. É necessário que pensemos nessas intervenções como formas de trocas de experiências envolvendo o design e o artesanato, e isso requer necessariamente que pensemos na possibilidade de trocas de saberes entre designers e artesãos.

Quando consideramos que ambos (artesão e designer) constroem-se a si mesmos enquanto constroem uma peça, entendemos que tal experiência não se mede por um método unificado, pronto, rígido. Mas, talvez, por uma sucessão de métodos que se interpõem ao sabor dos achados que somente são possiveis na situação vivenciada por ambos.

No modelo atual de intervenção junto aos grupos de artesãos, o designer atua de forma a coordenar uma série de transformações que serão construídas no fazer do artesão a fim de que o produto artesanal passe a atender às necessidades de estilo, forma, acabamento, novidade etc. Dessa maneira, a relação designer/artesão corresponde a uma relação pedagógica. No entanto, é preciso levar em conta que o ato de ensinar "novos processos" ou "formas de inovação" para o desenvolvimento de produtos requer que o designer, antes de tudo, apreenda os processos originais a fim de perceber quais são as possibilidades e os limites de cada artesão para que a intervenção ocorra. 
É interessante refletir sobre a relação ensino/aprendizado presente na vivência entre designers e artesãos a partir dos estudos de Paulo Freire, quando ele coloca que é preciso que "desde os começos do processo vá ficando cada vez mais claro que, embora diferentes entre si, quem forma se forma e se 're-forma' ao formar e quem é formado forma-se e forma ao ser formado" (FREIRE, 2011, p. 25). Esse é o princípio do que ele chama de "pedagogia da autonomia", uma pedagogia fundada na ética, no respeito à dignidade e à própria autonomia do educando.

Considerando que na prática cotidiana os projetos são conduzidos pelo designer, seria interessante pensá-lo como mediador ou facilitador dos processos, uma vez que cabe a ele, de acordo com as metodologias atuais, identificar as necessidades dos grupos, projetar os produtos e acompanhar seu desenvolvimento levando em conta as reações e as particularidades do comportamento dos artesãos. 0 que implica na adoção de uma conduta, por parte do designer, que seja sensivel às necessidades dos artesãos, percebendo-o não como um mero instrumento para se chegar ao produto, mas como o real motivo das intervenções. Logo, haveriamos de repensar as intervenções no sentido de colocar o artesão antes do produto, e não o contrário.

É importante lembrar que 0 artesão não é operário, não recebe salário fixo e não tem patrão, ou seja, ele é o dono de seu saber, de seu fazer e, principalmente, de seu tempo. Então, cabe questionar: como o designer considera isso? No design e para o designer, o foco deve ser sempre o produto e sua performance, e também o que se refere à satisfação das necessidades (objetivas e subjetivas) dos consumidores. Entretanto, quando a base do projeto é o artesanato, o foco não deve se resumir ao produto, mas aos produtores, aos artesãos, que são os agentes efetivos na construção e na concepção dos produtos. Sobre isso, Mendes (2011) coloca que:

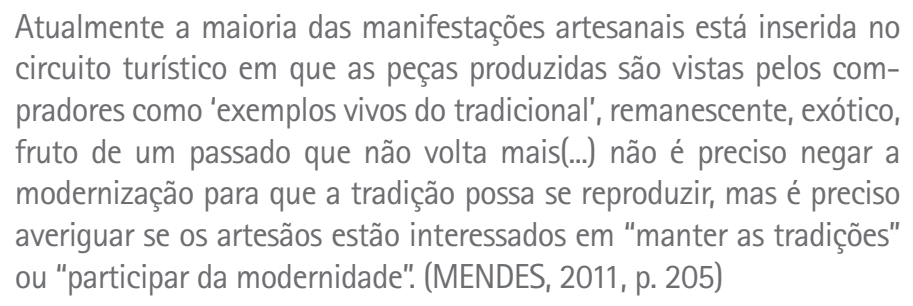
circuito turístico em que as peças produzidas são vistas pelos compradores como 'exemplos vivos do tradicional', remanescente, exótico, fruto de um passado que não volta mais(...) não é preciso negar a modernização para que a tradição possa se reproduzir, mas é preciso averiguar se os artesãos estão interessados em "manter as tradições" ou "participar da modernidade". (MENDES, 2011, p. 205)

Em seu estudo, Mendes (2011) apresenta alguns casos de descaracterização da louça produzida pelas artesãs da localidade de Córrego de Areia, distrito do município de Limoeiro do Norte que fica a 204 km de distância de Fortaleza. A autora expõe uma situação recorrente quando 0 assunto é intervenção de design no artesanato: a renovação dos produtos e a inserção de referenciais estéticos com os quais as artesãs nem sempre se identificam.

A autora salienta que, na atualidade, 0 artesanato desempenha um papel econômico e social, pois ele se define como expressão de uma cultura ao mesmo tempo que é considerado bem de consumo, cuja comercialização garante a sobrevivência do artesão (VIVES, 1993 apud MENDES, 2011). No entanto, no que diz respeito à produção artesanal, por mais que o mercado disponha de aparatos tecnológicos, o processo e as metodologias de confecção das peças continuam os mesmos das gerações anteriores, revelando que "a continuidade da tradição familiar não foi perdida" (MENDES, 2011, p. 75). Por outro lado, há a atualização dos produtos por meio de desenhos, formas, referências e cores que é geralmente direcionada pelos designers.

Nesse sentido, a consideração do artesão como foco das intervenções no lugar do produto exige que repensemos o papel do designer no contexto dessas intervenções. Este, além de profissional detentor de conhecimentos sobre metodologia projetual, atua, também, como facilitador na transmissão desses conhecimentos sobre o design para os artesãos. 
Quando nos defrontamos com situações nas quais os próprios designers se questionam sobre as possibilidades e os limites que eles possuem ao lidar com 0 artesanato, percebemos que há uma nítida preocupação desses profissionais e, ao mesmo tempo, certa insegurança ao lidar com esse bem, como podemos observar em alguns dos depoimentos já mencionados:

Até que ponto o designer tem autonomia para desenvolver um trabalho de vanguarda? Até que ponto a nossa criatividade nos permite extrapolar alguns limites? Ou seja, como posso utilizar elementos que casem com 0 desejo do público da Ceart? (Designer 3, em 14 de agosto de 2013)

Temos várias funções, pois temos que atender vários desejos, o do público-alvo e o do artesão, a questão social etc. (Designer 6, em 14 de agosto de 2013).

Retomando algumas colocações nas quais os designers questionam sua própria atuação, podemos perceber que eles não enxergam sua atuação junto aos artesãos como pedagógica. Para eles, é latente apenas a prática profissional e burocrática que envolve seu trabalho nos grupos, sendo o resultado disso uma ou mais coleções aprazíveis ao mercado e adequadas às exigências das entidades que fomentam as intervenções. Ao mesmo tempo que têm consciência de que precisam "atender vários desejos, o do público-alvo e o do artesão, a questão social etc.", eles não sabem o que priorizar e como conciliar todos esses aspectos. De fato, essa situação provoca um grande dilema para o designer comprometido com o trabalho e para a instituição.

Levando-se em conta que o designer possui uma formação eminentemente voltada para a criação e o desenvolvimento de bens materiais para o mercado e que sua atuação é, a priori, totalmente voltada para atender às necessidades da indústria, não é difícil entender por que eles enfrentam esses conflitos ao lidar com o artesanato. Essa é uma realidade para a qual ele não foi preparado. Dessa forma, produzir a partir do artesanato e lidar com os artesãos é um desafio para o designer contemporâneo, haja vista que o artesanato possui não só um papel material ou econômico, mas carrega consigo o fator cultural e humano, mais do que qualquer outro tipo de bem produzido pela indústria.

No trabalho com o artesanato, os designers veem-se responsáveis por várias funções, mas não se situam em relação a elas, não conseguem definir onde começa e onde termina o seu papel. Ao conversar com um grupo de estudantes do curso de Design-Moda da Universidade Federal do Ceará, eles apontaram várias dúvidas acerca de sua própria atuação em relação ao artesanato e ao artesão. Um desses estudantes expôs uma questão importante e que, talvez, esteja no cerne dos entraves que muitas vezes ocorrem no cotidiano da relação designer/artesão:

A gente não faz um curso de licenciatura, a gente não sabe nada sobre a construção do conhecimento humano, nossa formação é voltada para a lida com produtos e tudo o que tem a ver com ele. (Estudante 1, aluno do

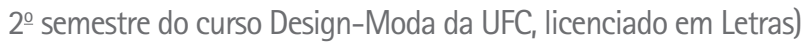

A distinção colocada pelo estudante entre o curso de design e o curso de licenciatura é bastante pertinente para que vislumbremos as causas dos conflitos que emergem na relação entre designers e artesãos. É importante ressaltar, ainda, que tal observação foi exposta por um estudante de design já licenciado em letras e que, portanto, recebeu uma formação voltada para a prática do ensino. 0 estudante ressalta em seu depoimento que o desenvolvimento de produtos artesanais requer do designer um olhar voltado para algo além das características do produto, ou seja, para a formação humana, uma vez que o resultado obtido com esse tipo de trabalho depende, prioritariamente, do tipo de relação estabelecida entre designer e artesão.

Dessa forma, como vem sendo colocado ao longo deste artigo, cabe desenvolvermos um olhar mais atento à prática cotidiana do designer em sua relação com 
o artesão, a fim de que possamos dar novos passos no que se refere a ações mais eficazes na produção artesanal e que, portanto, tenham continuidade. É sabido que das muitas ações e dos projetos desenvolvidos com a finalidade de implementar 0 artesanato, valorizando-o e gerando renda para os artesãos, poucos são aqueles que alcançam resultados satisfatórios, como autonomia do grupo produtivo, continuidade dos trabalhos e envolvimento dos produtores (SILVA, 2011).

Considerando que o designer assume também uma atitude pedagógica em seu trabalho junto aos artesãos, é pertinente que pensemos sobre essa prática. Em alguns momentos do texto foi colocado que, por não (re)conhecerem seu papel pedagógico e também pela falta de discernimento sobre a questão do "ensino", os designers, na maioria das vezes, agem apenas no sentido de "adestrar/treinar" os artesãos para 0 manuseio das ferramentas do design, quando, para Freire (2002), ensinar não é transferir conhecimento, mas criar possibilidades para sua própria construção. Essa falta de experiência dos designers com tal noção de ensino contribui para a manutenção do paradoxo presente no modo de intervenção no ofício dos artesãos: foco no produto e não naquele que o produz.

\section{O papel do designer na perspectiva da educação emancipatória}

Conforme Freire (2011), educar ou ensinar é muito mais do que puramente treinar o educando no desempenho de suas destrezas, mas permitir que ele vá além da técnica e da reprodução e passe à criação, sendo, portanto, autor daquilo que constrói e se reconheça nisso (MARX, 2012).

Nesse sentido, faz-se necessário pensarmos a relação designers/artesãos sob a perspectiva da educação emancipatória. Uma vez que as políticas de implementação do artesanato se predispõem a promover o trabalho do artesão de maneira que ele possa impulsionar seu ofício, gerando ocupação e renda para si próprio e seus companheiros, faz-se necessária uma ação mais embasada, na qual os artesãos possam se reconhecer em seu trabalho, valorizando-o e valorizando-se ao mesmo tempo. Porém, o que se observa, na maioria das vezes, é a alienação do gesto criador do artesão, que passa a ser responsabilidade do designer que medeia as ações das entidades.

Pelo que se pôde observar ao longo do estudo, não são todos os designers que respeitam o saber e o potencial criativo do artesão. Por outro lado, há, também, muitos artesãos que passam a supervalorizar o saber do designer, colocando-o acima do seu. Isso é ainda mais grave, uma vez que o artesão que se coloca nessa posição passa a desacreditar o seu próprio trabalho e coloca sobre o outro (designer) a responsabilidade por seu sucesso ou fracasso. Há, ainda, artesãos que atribuem a beleza de suas peças a um determinado designer ou, também, grupos de artesãos que param de produzir por não conseguirem desenvolver sozinhos peças diferenciadas (SILVA, 2011).

Essa dependência do artesão em relação ao designer não prejudica apenas o trabalho do artesão, mas também o do designer, uma vez que este se vê numa posição na qual supostamente "pode criar o que quiser" e deixa de levar em conta o contexto e o modo de produzir dos artesãos e, portanto, suas limitações. Isso provoca insuficiência não só no resultado do trabalho, mas também na relação entre os sujeitos envolvidos. Dessa forma, é preciso que o designer não se coloque ou não se deixe colocar na posição de dominação, mas ao contrário, que esteja ao lado do artesão para compreender seus interesses, suas habilidades e seus anseios.

Sobre esse processo de ensino/aprendizagem, Freire (2011) coloca que a educação para a autonomia requer uma atitude de mão dupla. Não se pode pensar em um processo de ensino no qual aquele que aprende também não interfira nesse aprendizado, pois aquele que ensina aprende durante o processo e o que aprende também ensina. Logo, na relação entre designers e artesãos, há que se pensar mais em intersecções de saberes do que em superioridade do saber acadêmico em relação ao saber empírico 
do artesão, pois não há como desenvolver produtos artesanais sem levar em conta o saber e a técnica dos artesãos antes de tudo.

Não são poucos os questionamentos acerca das intervenções no artesanato. Há estudiosos e pesquisadores que preferem não se pronunciar sobre essa questão e, ainda, outros que defendem que essas ações devam ser mediadas não apenas por designers, mas também por antropólogos, sociólogos e psicólogos ${ }^{4}$.

Em nossa perspectiva, os questionamentos não devem estar centrados na abolição ou na permanência das políticas, tampouco na extinção da intervenção na produção artesanal, mas nos métodos que são utilizados para tais ações. No como ocorrem essas intervenções é que deve estar o foco de nossas reflexões. Dessa forma, acreditamos que a crítica não deve ser dirigida ao designer em si, mas ao modo como ele é "preparado" para lidar com o artesanato e, principalmente, com os artesãos.

Nesse sentido, pressupõe-se que as políticas e intervenções no artesanato não devem deixar de existir, mas ser regidas por critérios que levem em conta saberes que vão além da metodologia projetual ${ }^{5}$. É aí que entram outros conhecimentos de cunho antropológico, sociológico, psicológico e pedagógico, que são imprescindíveis na formação do designer que pretende lidar com o trabalho artesanal.

De acordo com Gramsci (1988), é necessário possibilitar o acesso democrático a um saber que permita ao indivíduo participar ativamente dos processos político e produtivo, enquanto compreende as relações sociais que determinam seu modo de vida, sua visão de mundo e sua consciência. Conforme a colocação do autor, podemos compreender a necessidade do exercício da interdisciplinaridade envolvida no processo de ensino/aprendizagem de modo geral e que pode ser adotada na relação entre designers e artesãos. Para Gramsci (1988), são as exigências da divisão social do trabalho que determinam a distribuição do saber de forma diferenciada, segundo as necessidades de instrumentalizar os indivíduos para que eles ocupem lugares distintos na hierarquia social.

Pelos estudos em campo, foi possivel observar que, à medida que a presença do designer passa a ser algo constante no cotidiano de trabalho dos artesãos, há um processo de separação de elementos que antes eram complementares no oficio do artesão: o saber e o fazer. Para Adorno e Horkheimer (1988), o conceito de esclarecimento não pode ser reduzido à noção tecnicista, como a apregoada pela sociedade pós-iluminista, em que é associado à dissolução dos mitos e da imaginação em prol do saber experimental e calculado, ou seja, meramente racional. De acordo com os estudiosos, essa previsibilidade calculada, baseada em um tipo de saber calcado no pragmatismo, impede o desenvolvimento da imaginação, da inventividade e da criatividade, impossibilitando ou limitando os passos dos indivíduos rumo a novas descobertas.

A forma de apreensão do saber de modo consciente e, portanto, crítico, por parte do indivíduo é o que Adorno e Horkheimer (1988) chamam de estado de maioridade. Para eles, o homem alcança seu estado de maioridade quando faz uso autônomo da razão, quando desenvolve sua visão crítica e passa a pensar de forma livre, ou seja, para além do que já está posto pela ordem social.

Mas no caso em questão, o que ocorre, na maioria das vezes, é que a participação do designer como agente da inovação e da criatividade de novos produtos (a partir da técnica do artesão) faz com que o artesão fique à margem do processo criativo e passe a atuar apenas como mão de obra ou como mero reprodutor técnico daquilo que foi criado por outrem, no caso, o designer. Em outras palavras, o artesão passa a ser alienado de sua própria inventividade e criatividade e passa a ser mero executor do que é projetado pelo designer.

Além da violência simbólica (BOURDIEU, 1989) à qual o artesão é submetido nesse processo, estão as consequências que ela provoca no que diz respeito ao trabalho realizado pelo artesão e à sua visão de mundo. Ao pensarmos que ao designer é atribuída toda a responsabilidade de reorientar o modo de produzir do artesão, impondo a ele o seu ponto de vista sobre o tipo de artesanato que será produzido, sob a alegação de que o produto será mais valorizado comercialmente e que isso acarretará 
em benefícios, como maior geração de renda para o grupo produtivo local, o artesão é constrangido a desconfiar de seu potencial inventivo e, portanto, crítico, passando a transferir para o designer toda a responsabilidade em relação à criação, à beleza e à inovação das peças. Com isso, se esvai também seu senso crítico e a consciência de si mesmo como ser autônomo, livre.

Nesse contexto, o artesão, que muitas vezes não é letrado, não anda de carro nem mora na cidade, transfere para o designer não só o gesto criador que nutre a produção artesanal, mas também o mérito pela produção e sua autoestima. Ou seja, o trabalho que antes fazia parte das vivências, das experiências e do modo de vida do artesão passa a ser algo estranho e diferente dele; algo que ele executa, mas que não mais the pertence, o trabalho torna-se estranho, exterior, alheio ao produtor (RANIERI, 2001).

Quando contratados por instituições para implementar a produção de algum grupo, seja criando novos produtos, seja desenvolvendo novas formas de potencializar a sua técnica, o designer atua mesmo como instrutor, professor, alguém responsável por "transmitir" conhecimentos aos artesãos. Uma vez que o designer entende de design e 0 artesão entende da tipologia artesanal, no contato entre designer e artesão há, necessariamente, uma troca de saberes na qual o designer vai observar, analisar, compreender cada gesto e cada ferramenta utilizada pelo artesão, cada movimento que este desenvolve para conceber a peça. Por outro lado, 0 artesão terá de compreender, assimilar e principalmente se envolver com os projetos apresentados pelo designer a fim de que possa executá-los. Logo, essa troca de saberes entre ambos os profissionais é inevitável, real e necessária à atividade no contexto das políticas intervencionistas.

Para compreendermos melhor como se dá a intersecção de saberes entre designers e artesãos, podemos partir das considerações de Adorno (2003): para ele, o processo de construção do saber requer o embate entre elementos contraditórios a fim de que, por meio da negação, se construa a afirmação. Ele coloca que a experiência formativa seria, portanto, uma reelaboração do presente a partir de sua relação com o passado, isto é, uma apreensão do real como se fosse também histórico e, portanto, acessivel a uma práxis transformadora.

A experiência formativa seria, nesses termos, um movimento pelo qual a figura realizada seria confrontada com sua própria limitação. Por isso, esse método da formação crítica é "negativo"; o que é torna-se efetivamente o que é pela relação com o que não é. 0 dinamismo do processo é de recusa do existente, pela via da contradição e da resistência. (ADORNO, 2003, p. 24)

Por outro lado, Adorno (2003) coloca que a educação não é necessariamente um fator de emancipação. Ele adverte contra os aspectos negativos do processo educacional que não leva em conta o esclarecimento, mas a apropriação do conhecimento técnico e alerta para a necessidade de se empreender uma educação que favoreça a emancipação humana, e não o aprisionamento do senso crítico. A partir disso, podemos inferir sobre o caráter construtivo da troca e não da dominação de saberes entre designers e artesãos, uma vez que, conforme Adorno (2003), a troca de saberes e 0 confronto de ideias fomenta a criatividade.

\section{Considerações finais}

Ao percebermos a complexidade que envolve as relações vivenciadas entre designers e artesãos no contexto das transformações ocorridas no mercado e, portanto, no mundo do trabalho da atualidade, faz-se latente a preocupação com o tipo de formação do designer que irá atuar junto aos artesãos, no intuito de promover as atividades. 
Destarte, não resta dúvida de que os designers que se predispõem a trabalhar com 0 artesanato e a atuar junto aos artesãos, seja mediando as ações de políticas públicas, seja contratando o serviço do artesão, na maioria das vezes, agem de forma "bem-intencionada". Muitas vezes há, por parte desses profissionais, a preocupação em valorizar o trabalho dos artesãos, porém, eles não possuem os recursos pedagógicos necessários para isso, ou seja, a formação adequada para exercer a função de mediadores das ações empreendidas por políticas como a que foi apresentada ao longo do trabalho.

Dessa forma, pode-se concluir que os designers também carecem de uma formação emancipatória, ou seja, para além do tecnicismo e do economicismo que são inerentes ao campo do design. Somente com isso, pode-se vislumbrar a possibilidade de o designer atuar junto aos artesãos valorizando-os e incentivando-os como criadores, evitando sua dependência e, por conseguinte, a desvalorização de seu potencial inventivo, criativo e crítico.

\section{NOTAS}

${ }^{[1]}$ Este texto é parte da minha tese de doutorado realizada no Programa de Pós-Graduação em Educação Brasileira da Universidade Federal do Ceará entre os anos de 2011 e 2014

[2] Projeto Artesanato Competitivo da Ceart e o Projeto de Qualificação em Fundamentos do Design para Artesãos do Estado do Ceará, realizados pela parceria entre Ceart e UFC

${ }^{[3]}$ No Ceará, as principais entidades voltadas à atuação no campo do artesanato são o Serviço Brasileiro de Apoio às Micro e Pequenas Empresas (SEBRAE) e a Central de Artesanato do Ceará (Ceart).

${ }^{[4]}$ Trago aqui este questionamento, pois o mesmo me foi feito em uma de minhas conferências sobre este tema, durante a qual um dos presentes perguntou se eu não achava que os artesãos precisavam de acompanhamento psicológico para elevação de sua autoestima.

[5] 0 processo em design envolve a relação do designer com o produto para o gerenciamento e o controle das situações geradas durante o desenvolvimento do produto, é o mesmo que chamamos de atividade projetual (MONTEMEZ7O, 2003). De acordo com Baxter (1998), projetar significa ter uma conduta sistematizadora própria para a resolução de problemas, cujo objetivo é a transformação de necessidades do mercado em produtos ou serviços economicamente viáveis. 


\section{REFERÊNCIAS}

ADORNO, T. W. Educação e emancipação. São Paulo: Paz e Terra, 2003.

W.; HORKHEIMER, Marx. Dialética do esclarecimento. Tradução de Guido de Almeida, Rio de Janeiro: J. Zahar, 1988

BOURDIEU, Pierre. O poder simbólico. Rio de Janeiro: Difel, 1989.

CANCLINI, Nestor Garcia. Culturas híbridas. São Paulo: Edusp, $2008 b$.

ESTRADA, Maria Helena. Sete anos de transformações: design, artesanato, indústria e mercado. In: Revista Arc Design, n. 38. São Paulo: Quadrifólio Editora, 2004.

FREIRE, Paulo. Pedagogia da autonomia: saberes necessários à prática educativa. São Paulo: Paz e Terra, 2002.

Pedagogia do oprimido. São Paulo: Paz e Terra, 2011.

FREITAS, Ana Luiza Cerqueira. Design e artesanato: uma experiência da metodologia de projeto de produto. Belo Horizonte, 2006. Dissertação (Mestrado em Engenharia) - Programa de Pós-Graduação em Engenharia - PPGE, Escola de Engenharia da Universidade Federal de Minas Gerais.

GONÇALVES, H. de A. Manual de projetos de pesquisa científica. São Paulo: Avercamp, 2005.

GRAMSCl, Antonio. Os intelectuais e a formação da cultura. Rio de Janeiro: Civilização Brasileira, 1988.

LIMA, Ricardo Gomes. 0 povo do candeal: sentidos e percursos da louça de barro. Rio de Janeiro,

2006. Tese (Doutorado em Antropologia) - Programa de Pós-Graduação em Sociologia e Antropologia Universidade Federal do Rio de Janeiro.

MARX, Karl. 0 capital: crítica da economia política: livro 1/Karl Marx; tradução de Reginaldo Sant'anna 30a. ed. Rio de Janeiro: Civilização Brasileira, 2012.

MENDES, Francisca R.N. Modelando a vida no córrego de areia: tradição, saberes e itinerários das louceiras. Fortaleza: Expressão Gráfica Editora, 2011.

MONTEMEZZO, Maria Celeste. Diretrizes metodológicas para o projeto de produtos de moda no âmbito acadêmico. Bauru, 2003. Dissertação (Mestrado em Desenho Industrial). Universidade Estadual Paulista - UNESP.

RANIERI, Jesus. A câmara escura: alienação e estranhamento em Marx. São Paulo: Boitempo, 2001.

SILVA, Emanuelle Kelly. Quando a cultura entra na moda: a mercantilização do artesanato e suas repercussões no cotidiano de bordadeiras de Maranguape. Fortaleza: Ed. UFC, 2011. 